\title{
Excessive Internet Use: Implications for Sexual Behavior
}

\author{
MARK GRIFFITHS, Ph.D.
}

\begin{abstract}
The Internet appears to have become an ever-increasing part in many areas of people's dayto-day lives. One area that deserves further examination surrounds sexual behavior and excessive Internet usage. It has been alleged by some academics that social pathologies are beginning to surface in cyberspace and have been referred to as "technological addictions." Such research may have implications and insights into sexuality and sexual behavior. Therefore, this article examines the concept of "Internet addiction" in relation to excessive sexual behavior and Internet pornography, as well as examining newer areas of Internet sexuality such as "online relationships" and sexually-related Internet crime (e.g., "cyberstalking").
\end{abstract}

\section{SEXUALLY-RELATED USES OF THE INTERNET}

B EFORE EXAMINING THE "addictiveness potential" of the Internet and its relationship with sexuality, it would appear wise to examine all the different ways that the Internet can be used for sexually-related purposes as it is probably the case that only some of these activities may be done to excess and/or be potentially addictive. The Internet can (and has) been used for a number of diverse activities surrounding sexually motivated behavior.

- Seeking out sexually-related material for educational use. This includes those seeking information regarding (a) sexual health promotion (e.g., information about contraception, sexually transmitted diseases, etc.), (b) self-help/diagnosis (e.g., advice about sexual dysfunctions, sexual diseases, etc.), and (c) scientific research (e.g., reports of studies in the area of sexology, national reports on sexual behavior, etc.). These may take the form of either standalone Web pages or may be incorporated within Usenet discussion groups.
- Buying or selling sexually-related goods for further use offline. This includes the buying or selling of goods for (a) educational purposes (e.g., books, videos, CD-ROMs, etc.), (b) entertainment/masturbatory purposes (e.g., magazines, books, videos, CDROMs, etc.), and (c) miscellaneous purposes (e.g., sex aids/toys, contraception, aphrodisiacs, etc.).

- Visiting and/or purchasing goods in online virtual sex shops. Visiting a virtual sex shop may be done for either voyeuristic purposes ("window shopping") or for the sole intention of actually buying goods for use offline.

- Seeking out material for entertainment/masturbatory purposes for use online. This can either be primarily image-based (e.g., pornographic websites offering picture libraries, video clips, videos, live online strip shows, live voyeuristic Web-cam sites, etc.) or text-based (e.g., chat rooms, Usenet discussion groups, etc.)

- Seeking out sex therapists. This may involve either individuals or couples seeking out an online sex therapist for advice about sex and/or relationship problems. 
- Seeking out sexual partners for an enduring relationship (i.e., a monogamous partner) via online dating agencies, personal advertisements/"lonely hearts" columns and / or chat rooms.

- Seeking out sexual partners for a transitory relationship (i.e., escorts, prostitutes, swingers) via online personal advertisements/"lonely hearts" columns, escort agencies and/or chat rooms.

- Seeking out individuals who then become victims of sexually-related Internet crime (online sexual harassment, cyberstalking, paedophilic "grooming" of children).

- Engaging in and maintaining online relationships via E-mail and/or chat rooms.

- Exploring gender and identity roles by swapping gender or creating other personas and forming online relationships.

- Digitally manipulating images on the Internet for entertainment and/or masturbatory purposes (e.g., celebrity fake photographs where heads of famous people are superimposed onto someone else's naked body).

On first examination-and by evaluating the relatively sparse literature in this area-it would appear that excessive, addictive, obsessive, and/or compulsive Internet use only applies to some of these behaviors. The most likely behaviors include the use of online pornography for masturbatory purposes, engaging in online relationships, and sexually-related Internet crime (e.g., cyberstalking). Before looking at these three areas in more detail, a brief overview of Internet addiction will follow.

\section{INTERNET ADDICTION}

One area that Internet sexuality has been discussed academically is that of "Internet addiction." Research into this area is at present sparse but growing. For many people, the concept of Internet addiction is something that they cannot accept because of their mindset that addiction involves the taking of drugs. Indeed, most official definitions concentrate on drug ingestion. Despite opposition to the concept of behavioral (i.e., non-chemical) addic- tions, $^{1,2}$ there is now a growing movement ${ }^{3-6}$ to view a number of behaviors as potentially addictive including many behaviors that do not involve the ingestion of a drug. These include behaviors as diverse as gambling, overeating, sex, exercise, and computer game playing. ${ }^{6}$ Internet addiction is another such area because it has been alleged by some academics that social pathologies (i.e., technological addictions) may be beginning to surface in cyberspace. ${ }^{7-18}$

Technological addictions are operationally defined as non-chemical (behavioral) addictions that involve human-machine interaction. They can either be passive (e.g., television) or active (e.g., computer games) and usually contain inducing and reinforcing features that may contribute to the promotion of addictive tendencies. ${ }^{19}$ Technological addictions can be viewed as a subset of behavioral addictions ${ }^{5}$ and feature core components of addiction, (i.e., salience, mood modification, tolerance, withdrawal, conflict and relapse). ${ }^{6,20}$ Any behavior (e.g., Internet use) that fulfils these six criteria are operationally defined as addictions. These core components are expanded upon below in relation to Internet sex of whatever type it happens to be (e.g., downloading pornography, cypersex relationships, etc.).

- Salience-This occurs when Internet sex becomes the most important activity in the person's life and dominates their thinking (preoccupations and cognitive distortions), feelings (cravings), and behavior (deterioration of socialized behavior). For instance, even if the person is not actually on their computer engaged in Internet sex they will be thinking about the next time they will be.

- Mood modification-This refers to the subjective experiences that people report as a consequence of engaging in Internet sex and can be seen as a coping strategy (i.e., they experience an arousing "buzz" or a "high" or paradoxically tranquilizing feel of "escape" or "numbing").

- Tolerance-This is the process whereby increasing amounts of Internet sex are required to achieve the former mood modificating effects. This basically means that for someone engaged in Internet sex, they 
gradually build up the amount of the time they spend in front of the computer engaged in the behavior.

- Withdrawal symptoms-These are the unpleasant feeling states and/or physical effects that occur when Internet sex is discontinued or suddenly reduced, (e.g., the shakes, moodiness, irritability, etc.).

- Conflict-This refers to the conflicts between the Internet user and those around them (interpersonal conflict), conflicts with other activities (job, social life, hobbies, and interests) or from within the individual themselves (intrapsychic conflict and/or subjective feelings of loss of control) that are concerned with spending too much time engaged in Internet sex .

- Relapse-This is the tendency for repeated reversions to earlier patterns of Internet sex to recur and for even the most extreme patterns typical of the height of excessive Internet sex to be quickly restored after many years of abstinence or control.

Young ${ }^{21}$ claims Internet addiction is a broad term that covers a wide variety of behaviors and impulse control problems. She claims is further categorized by five specific subtypes.

- Cybersexual addiction: Compulsive use of adult websites for cybersex and cyberporn.

- Cyber-relationship addiction: over-involvement in online relationships.

- Net compulsions: obsessive online gambling, shopping, or day-trading.

- Information overload: compulsive web surfing or database searches.

- Computer addiction: obsessive computer game playing (e.g., Doom, Myst, Solitaire, etc.)

Only two of these specifically refer to potential sexually-based addictions (i.e., cybersexual addiction and cyber-relationship addiction), but Young's classification does raise the question of what people are actually addicted to. On a primary level, is it the sexually-related behavior or is it the Internet? In reply to Young, Griffiths ${ }^{22}$ has argued that many of these excessive users are not "Internet addicts" but just use the Internet excessively as a medium to fuel other addictions. Griffiths argues that a gambling addict or a computer game addict is not addicted to the Internet. The Internet is just the place where they engage in the behavior. The same argument can be applied to Internet sex addicts. However, there are case study reports of individuals who appear to be addicted to the Internet itself. These are usually people who use Internet chat rooms or play fantasy role playing games-activities that they would not engage in except on the Internet itself (some of which are sex-related). These individuals to some extent are engaged in text-based virtual realities and take on other personas and social identities as a way of making themselves feel good about themselves.

In these cases, the Internet may provide an alternative reality to the user and allow them feelings of immersion and anonymity which may lead to an altered state of consciousness. This in itself may be highly psychologically and/or physiologically rewarding. The anonymity of the Internet has been identified as a consistent factor underlying its excessive use. ${ }^{17,23}$. This is perhaps particularly relevant to those using Internet pornography. There may be many people who are using the medium of the Internet because (a) it overcomes the embarrassment of going into shops to buy pornography over the shop counter, and (b) it is faster than waiting for other non-faceto-face commercial transactions (e.g., mail order). Anonymity may also encourage deviant, deceptive, and criminal online acts such as the development of aggressive online personas or the viewing and downloading of illegal images (e.g., pornography) ${ }^{24}$. The issue of Internet pornography will be returned to in a later section.

\section{Survey research on excessive Internet use for sexual purposes}

There have been few studies of excessive Internet use although two studies have examined excessive Internet use among a student population and found that a small proportion of users admitted using the Internet for sexual purposes. Morahan-Martin and Schumacher ${ }^{15}$ examined what they termed "pathological In- 
ternet use" in 277 college students using a 13item questionnaire (all those who scored four or more affirmative answers were defined as pathological Internet users). Pathological Internet users accounted for $8.1 \%$ of the total sample and were more likely to be male $(12.2 \%$ males; $3.2 \%$ females) and to use technologically sophisticated channels and online games. Other defining characteristics of pathological Internet users were that they were more likely to use a wide variety of Internet services, and were more likely to use the Internet to meet new people, get emotional support, talk to others with the same interest, to play interactive games like MUDs (Multi-User Domains), to gamble, and to engage in net-sex.

Scherer and Bost ${ }^{25}$ surveyed 531 students about their Internet use and developed a checklist of 10 clinical symptoms to parallel the symptoms of substance abuse and dependency. Students who reported three or more symptoms were classed as "Internet dependent" (ID). Results indicated that 49 respondents $(13 \%)$ of weekly Internet users scored three or more on the dependency checklist and that the majority of these were male $(71 \%)$. It was also reported that the ID participants used less popular services on the Internet (games, bulletin boards, IRC, MUDs, etc), and that they were more likely to have online relationships. Although unrepresentative of the general public, college students are considered high-risk for Internet problems because of ready access and flexible time schedules. ${ }^{26}$

Young $^{17}$ found that serious relationship problems were reported by $53 \%$ of the 396 case studies of "Internet addicts" interviewed, with marriages and intimate dating relationships most disrupted due to cyberaffairs and online sexual compulsivity. Further to this, in a study of Internet users, Cooper, Putnam, Planchon, and Boies ${ }^{13}$ found that (a) $8.5 \%$ manifested signs of sexual compulsivity, and (b) $22 \%$ had engaged in online sexual pursuits that had actually jeopardized at least one important dimension of their lives. Cooper et al. ${ }^{13}$ went on to claim that a significant minority of Internet users are likely to be addicted to either the Internet, cybersex, cyber-relationships, or some combination of the three.

None the surveys to date (see Griffiths ${ }^{10}$ for an overview) conclusively show that Internet addiction exists or that Internet sex addiction is problematic to anyone but a small minority. At best, they indicate that Internet addiction may be prevalent in a significant minority of individuals but that more research using validated survey instruments and other techniques (e.g., in-depth qualitative interviews) are required. Griffiths ${ }^{22}$ has also noted that the problem with the criteria in most of the survey studies to date is that they (a) have no measure of severity, (b) have no temporal dimension, (c) have a tendency to overestimate the prevalence of problems and (d) take no account of the context of Internet use. Case studies of excessive Internet users may provide better evidence of whether Internet sex addiction exists by the fact that the data collected are much more detailed. Even if just one case study can be located it indicates that Internet sex addiction actually does exist-even if it is unrepresentative. Griffiths ${ }^{10,27}$ has also argued that excessive usage in a majority of cases appears to be purely symptomatic but that for what appears to be an exceedingly tiny minority, the Internet may be addictive. Whether this is a bona fide addiction or not, some research $8,9,17,18,21$ has observed that heavy Internet users gradually spent less time with real people in their lives in exchange for solitary time in front of a computer and/or in online relationships.

\section{PORNOGRAPHY ON THE INTERNET}

It is often said that "sex sells" and nowhere is this more true than on the Internet. There are also those who might argue that "sex drives innovation" particularly when the case of pornography on the Internet is examined. From the earliest days of photography to the latest innovations in real-time, one-to-one video conferencing, sex has played a defining role in the development and advance of new communication technology. ${ }^{28}$ Although the pornography industry cannot be credited with inventing these new technologies, they were certainly the first to put them to profitable use. Pornographers have always been the first to exploit new publishing technologies whether it be photography, videotape, or the Internet. 
As a consequence, online sexual services include the conventional (e.g., Internet versions of widely available pornographic magazines like Playboy), the not so conventional (Internet versions of very hardcore pornographic magazines), and what can only be described as the bizarre (discussion groups such as alt.sex. bondage.goldenshowers.sheep). Further to this, there are also pornographic picture libraries (commercial and free-access), videos and video clips, live strip shows, live sex shows and voyeuristic Web-cam sites. It is estimated that the online pornography industry will reach $\$ 366$ million by $2001^{28}$ though other estimates already suggest it is worth $\$ 1$ billion. ${ }^{29}$ Further to this, the research company Datamonitor reported that sex accounts for $69 \%$ of spending on the Internet. ${ }^{29}$

Sprenger ${ }^{28}$ has argued that the 1980 s saw three main types of Internet user-government officials, university academics, and pornography-seekers (groups that Sprenger argues were not necessarily mutually exclusive). Today's online pornography community has its roots in the bulletin board systems that evolved separately from the Internet in the 1980s. They gave way to Usenet groups and free file transfer protocol (FTP) formats whereby users could exchange files over the Internet. The earliest pornography sites on the Internet were FTP sites run from college and university campuses. The pornography industry were one of the first industries to take advantage of this medium as they realised that the Internet had a huge marketing potential-especially with the illegal trade of in-copyright pictures on the free FTP sites and the eclectic mix of text, visuals, and FTP capabilities. There seems to be no precise record of when free pornographic FTP sites were overtaken by the pay-per-view sites but it was in 1995 that they started to spring up in noticeable numbers.

As the pay-per-view sites became more sophisticated, the pornography industry was the first to experience some of the problems such as overloaded servers and credit card processing. All the problems that e-business and ecommerce ventures face today, were first experienced by the pornography industry who continually pushed the envelope of streaming technology because of the potential huge prof- its to be made. ${ }^{28}$ In fact, two particular developments in current use (pay-per-click banner advertisements and real-time credit card processing) were both developed by technical expertise from within the pornographic industry. These developments have had significant impacts on the accessibility afforded to Internet users. Theoretical 24-hour constant access has the potential to stimulate excessive use which may in some circumstances lead to addictive and/or compulsive activity.

One of the main reasons that the pornography industry has such a vested interest in this area is that the buying of most products is hassle-free and anonymous over the Internet. However, buying pornography in the offline world may be embarrassing or stressful to the consumer particularly if they have to go to venues deemed to be "unsavoury." If pornography consumers are given the chance to circumvent this process, they invariably will.

Pornography and its distribution are now widespread on the Internet but how prevalent is Internet pornography? In the UK, a survey carried out by University of Middlesex in 1995, and replicated in 1997, analysed a million word searches on an Internet search engine and reported that over half of them were aimed at locating pornography. ${ }^{30}$ The top eight word searches were all pornography related. The study also reported that the pornography was more than just pictures of naked people but also included more worrying material. For instance, there was information for paedophiles on how to entrap and (in some instances) kill children. It was also claimed that some bulletin board sites gave information on how to have intercourse with amputees and accounts of child sexual abuse (which appeared to have been put there by the abusers themselves). Further to this, unsubstantiated reports by family campaigners have claimed that in between 1997 and 1999 there was a $40 \%$ increase in the number of UK Internet users who were regularly accessing hardcore pornography and paedophilic material. ${ }^{31}$ Academic researchers also claim that "sex" is the most searched for topic on the Internet, ${ }^{14}$ and as many as one-third of all Internet users visit some type of sexual site. ${ }^{32}$

Research has also revealed that Internet surfing has many parallels with road traffic. There 
appear to be identical patterns of congestion and "solid block motion" where everyone is forced to advance at the same speed. ${ }^{33}$ One web-traffic researcher, Bernardo Huberman (who works for Xerox Palo Alto Research Center) analyzed more than 500,000 visits to a major web portal and came to the conclusion that the Internet sex sites are the "undisputed kings" in selling advertizing space. Huberman noticed that Internet surfers typically click once or twice and then get out of a site. However, Huberman noted that some people were clicking up to 200 times and that nearly all of these instances were people accessing Internet sex sites. Further investigation revealed an amazingly sophisticated structure that led surfers deeper and deeper into the site. ${ }^{33}$ The "click counts" data collected by Huberman suggest that there is an almost compulsive element in accessing online pornography and that some people are very heavy users of these services. Such research cannot show that Internet pornography addicts exist but is at the very least indicative of repetitive, habitual, and/or pathological behavior.

\section{Children and Internet pornography}

One of the biggest fears among parents who are thinking of using the Internet is that their children will be exposed to pornography particularly because over 17 million children are using the Internet worldwide. ${ }^{34}$ Issues surrounding censorship are high on the moral agenda but preventing access to such sites is difficult. A major survey undertaken in 1998 in the United States by the Annenberg Public Pol- icy Center ${ }^{35}$ reported that $75 \%$ of parents were anxious about what their children might be exposed to on the Internet. To what extent is this fear justified? The media has certainly played a role in heightening parents' fears as twothirds of all newspaper articles about the Internet highlight negative aspects and one in four mentioned child pornography. ${ }^{35}$

This is not without some real fear as it is not at all difficult to access-especially with the development of powerful yet easy-to-use search engines. In fact, a survey by the National Opinion Poll (NOP) in June 1999 found that onethird of children in the United Kingdom had found content on the Internet that upset or embarrassed them-up from $20 \%$ in the previous survey. ${ }^{34,35}$ Of this material, $58 \%$ was described as being "rude." Given that the same NOP poll found that one in four UK children aged 7-16 years old (i.e., 3 million children) are regular Internet users with half of them doing it from home ${ }^{34}$ it therefore appears there may be widespread cause for alarm.

There are many steps a parent can take to prevent their child from accessing pornography.

- Reading guidelines for parents that detail issues and possible approaches for overseeing Internet use by children. These include those produced in offline versions (see Table 1) or those that can be found online. These include such sites as the Netparents resource collection (www.netparents.org/parentstips/resources.html), $\mathrm{NCH}$ Action for children site (www.nchafc.org.

Table 1. Guidelines for Children on How To Be Safe on the Internet

\footnotetext{
1. Never tell anyone that you meet on the Internet your home address, telephone number, or school's name unless you are given permission by a parent or carer.

2. Never send anyone your picture, credit card, or bank details (or anything else).

3. Never give your password to anyone-even your best friend.

4. Never arrange to meet anyone in person that you have met on the Internet without first agreeing it with your parent or carer.

5. Never stay in a chat room or in a conference if someone says or writes something that makes you feel uncomfortable or worried. Always report it to your parent or carer.

6. Never respond to nasty, suggestive or rude E-mails or postings in Usenet groups.

7. If you see bad language or distasteful pictures while you are online, always tell your parent or carer.

8. When you are online, always be yourself and do not pretend to be anyone or anything you are not.

9. Always remember that if someone makes you an offer that seems too good to be true-then it probably is.
}

Note: From NCH Action for Children, Children on the Internet: Opportunities and Hazards, 1998. 
uk/internet/index.html), and Schoolzone's resources (www.schoolzone.co.uk/resources/ safety_frame.htm).

- Be with your children at all times when they access the Internet.

- Join an Internet service provider that prevents its users from accessing such things.

- Install one of the many different types of blocking package on the market that filter content in some way. ${ }^{36,37}$ These include those that use lists of key words that you can define (e.g., Net Nanny), software packages that can block certain areas of the Internet such as Usenet groups or which restrict access at certain times (e.g., Cyber Patrol), packages that have a built-in censor to certain categories as defined by the maker of the package (SurfWatch) or packages that block access to certain file types like GIF and JPEG (most pornographic images are GIF or JPEG files). However, there may be a "technological generation gap" as the recent poll by NOP reported that children knew more about filtering software than their parents (Thompson, 1999).

Despite packages like Surfwatch and Net Nanny, which block access to pornographic sites, such packages can still be circumvented. There are also other packages like Babewatch which do the exact opposite (i.e., locate nothing but pornographic sites for the user). ${ }^{36,37} \mathrm{It}$ appears to be the case that parents are not as vigilant about their children's Internet use as they could be. For instance, a survey of 500 online households by the U.S.-based National Center for Missing and Exploited Children found that $20 \%$ of parents did not supervise their children's Internet use, while $71 \%$ of parents with children aged 14 or older said they had stopped monitoring their children's Internet use. ${ }^{34}$

\section{ONLINE RELATIONSHIPS}

Probably one of the most unexpected uses surrounding the growth of the Internet concerns the development of online relationships and their potentially addicting nature. Turned off by the sleazy hustling of offline singles bars, it appears that many people are now looking for love online. ${ }^{38}$ Now that Nora Ephron's film You've Got Mail has seeped into public consciousness, the idea of online relationships appears to be coming a more socially acceptable activity. It is hard to estimate the number of online relationships but one British newspaper reported that there had been more than one thousand weddings as a result of Internet meetings. ${ }^{39}$ From the outside it appears that the Internet has opened up a whole new world for "chat room conquistadors" and "e-mail femme fatales" with some media commentators claiming that cyberspace is becoming another singles bar as there are now numerous sites aimed at those who want romance and/or a sexual liaison. Some of these are aimed at single people (e.g., Widows, Thirtysomething UK, and Married with Kids) while others appear to encourage and facilitate virtual adultery (e.g., MarriedM4Affair, Cheating Wife, or Lonely Husband).

Young, Griffin-Shelley, Cooper, O'Mara, and Buchanan $^{40}$ define an online relationship (a "cyberaffair") as a romantic and/or sexual relationship that is initiated via online contact and maintained predominantly through electronic conversations that occur through E-mail and in virtual communities such as chat rooms, interactive games, or newsgroups. Young et al. $^{40}$ assert that what starts off as a simple E-mail exchange or an innocent chat room encounter can escalate into an intense and passionate cyberaffair and eventually into face-toface sexual encounters. Further to this, those in online relationships often turn to mutual erotic dialogue (often referred to as "cybersex"). In this instance, cybersex involves online users swapping text-based sexual fantasies with each other. These text-based interactions may be accompanied by masturbation. Online chat rooms provide opportunities for online social gatherings to occur almost at the push of a button without even having to move from your desk. Online group participants can-if they so desire-develop one-to-one conversations at a later point either through the use of continuous E-mails or by instant messages from chat rooms. It could perhaps be argued that electronic communication is the easiest, most disinhibiting, and most accessible way to meet potential new partners. 
Infidelity online-how and why does it occur?

There are a number of factors that make online contacts potentially seductive and/or addictive. Such factors include the disinhibiting and anonymous nature of the Internet. Furthermore, online relationships can be culturally diverse given the global nature of the Internet. This may be very exciting to those engaged in an online affair. Disinhibition is clearly one of the Internet's key appeals as there is little doubt that the Internet makes people less inhibited. ${ }^{41,42}$ Online users appear to open up more quickly online and reveal themselves emotionally much faster than in the offline world. What might take months or years in an offline relationship may only takes days or weeks online. As some have pointed out ${ }^{43}$ the perception of trust, intimacy, and acceptance has the potential to encourage online users to use these relationships as a primary source of companionship and comfort.

Some researchers have made attempts to explain how and why infidelity occurs online. Cooper ${ }^{12}$ proposed the Triple A Engine (Access, Affordability, and Anonymity), which he claims helps to understand the power and attraction of the Internet for sexual pursuits. Young ${ }^{24}$ also claimed to have developed a variant of the Triple A Engine which she called the ACE model (Anonymity, Convenience, Escape). Neither of these are strictly models as neither explains the process of how online relationships develop. They do, however, provide in acronym form, the main variables that account for acquisition and maintenance of online relationships. In order to understand the increased incidence of sex and infidelity online, Young claims her ACE Model explains how cyberspace creates a cultural climate of permissiveness that actually serves to encourage and validate sexually adulterous and promiscuous online behavior. ${ }^{24}$ The variables that can lead to virtual adultery outlined by Young and Cooper (i.e., anonymity, access, convenience, affordability and escape) do appear to provide the explanatory building blocks for the development of emotional and/or sexual relationships on the Internet. These are briefly looked at in turn as well as other reasons such as social acceptability and long working hours. It would also appear that virtual environments have the potential to provide short-term comfort, excitement, and/or distraction.

Access. Access to the Internet is now commonplace and widespread, and can be done easily from the home and/or the workplace. Given that prevalence of behaviors is strongly correlated with increased access to the activity, it is not surprising that the development of regular online use is increasing across the population. Increased accessibility may also lead to increased problems. Research into other socially acceptable but potentially addictive behaviors (drinking alcohol, gambling, etc.) has demonstrated that increased accessibility leads to increased uptake (i.e., regular use) and that this eventually leads to an increase in problemsalthough the increase may not be proportional. ${ }^{44}$

Affordability. Given the wide accessibility of the Internet, it is now becoming cheaper and cheaper to use the online services on offer. Although very excessive use will still lead to large monthly bills, for most people, the cost compared to either a telephone call and/or postage will be cheap to moderate.

Anonymity. The anonymity of the Internet allows users to privately engage in erotic textbased exchanges without the fear of being caught by a partner. This anonymity may also provide the user with a greater sense of perceived control over the content, tone, and nature of the online experience. ${ }^{40}$ The anonymity of the Internet often facilitates more honest and open communication with other users. ${ }^{43}$ Anonymity may also increase feelings of comfort because there is a decreased ability to look for, and thus detect, signs of insincerity, disapproval, or judgment in facial expression, as would be typical in face-to-face interactions. ${ }^{40}$

Convenience. Interactive online applications such as E-mail, chat rooms, newsgroups, or role-playing games provide convenient mediums to meet others. Online sexual behaviors will usually occur in the familiar and comfortable environment of home or workplace, thus reducing the feeling of risk and allowing even 
more adventurous behaviors that may or may not be potentially addictive.

Escape. For some, the primary reinforcement to engage in an online affair and/or cybersex is the sexual gratification they experience online. However, the experience of an online relationship itself, may be reinforced through a subjectively and/or objectively experienced "high." The pursuit of mood-modificating experiencies is characteristic of addictions. ${ }^{6,20}$ The mood-modificating experience has the potential to provide an emotional or mental escape and further serves to reinforce the behavior. Excessive involvement in this escapist activity may lead to addiction. ${ }^{10}$ While sexual fulfillment may provide either the initial or subsequent reinforcement, the more potent reinforcement is the ability to cultivate a subjective fantasy world. Online romantic and/or sexual behavior can provide a potent escape from the stresses and strains of real life. These activities fall on what Cooper, Putnam, Planchon, and Boies $^{13}$ describe as a continuum from life-enhancing to pathological and addictive.

Social acceptability. Social acceptability is also another factor to consider in this context. ${ }^{45}$ To some extent, online relationships (like the personal advertisements that are found in both local and national newspapers) can lead to many meetings and introductions. What is really interesting is how the perception of these types of activities have changed over the years. It was not long ago that personal advertisements and dating agencies were accused of preying on social inadequacy and emotional vulnerability. However, it is now accepted that there are lots of reasons why people are not in relationships these days. There are high-powered individuals who are career-minded and have little leisure time, others who have exhausted their social networks, and those who feel uneasy making contact with a stranger. It could also be a sign of things to come as children are exposed to technology earlier and so become used to socializing using computers as tools.

One problem with "lonely hearts" looking for romance on the Internet is that there is some anecdotal evidence that they be bombarded with adverts from prostitutes, hard-core porn actresses, and minors looking for sex. ${ }^{31} \mathrm{Ac}-$ cording to some recent press reports, many men who have used the Internet to find a partner have found that seemingly innocent comeons turn out to be from women looking for men who are willing to pay for sex. Policing the classified section is extremely difficult as those operating such services take their clients' word on trust. If these people are deliberately keeping the truth from the operator there is little the operator can realistically do.

Long working hours. In the UK, people are working longer hours and can have social relationships from the desktop. For these people, the Internet is ideal. Dating via your desktop may be a sensible option for workaholic professionals of the 1990s. It is effectively a whole new electronic "singles bar" that breaks down physical prejudices because of its text-based nature. For others, Internet interaction takes away the social isolation that we can all sometimes feel. There are no boundaries of geography, class, or nationality. It opens up a whole new sphere of relationship-forming. As mentioned previously, the whole process is also disinhibiting. People open up emotionally very quickly on the Internet as it is not as threatening as a letter, phone call, or face-to-face encounter. For those in online relationships, it is not usually an abnormal or online addictionIt is just a different way of living and interacting. Laying the foundations for a relationship in this way has become far more socially acceptable and will continue to be so. Most of these people are not societal misfits as is often claimed. They are simply using the technology as another tool in their social armoury.

\section{Types of online relationships}

A number of researchers have forwarded typologies of the different kinds of Internet users in relation to sexual and/or relationship activity. ${ }^{13,21,39}$ Cooper et al. ${ }^{13}$ suggest there are three types of cybersexual user (recreational, at risk, and compulsive) but this tells us little except about frequency of use. However, Griffiths ${ }^{39}$ has outlined three basic types of online relationships in relation to actual online behavior. 
The first one is purely virtual and involves two people who never actually meet. They engage in an online relationship that goes further than being pen-pals as the exchanges are usually very sexually explicit. Neither person wants to meet the other person and are engaged in the interaction purely for sexual kicks. It is not uncommon for these individuals to swap gender roles. The "relationships" may be very short lived and the people involved will usually have real-life partners. These people prefer the distance, relative anonymity, and control offered by the Internet and will prefer to confine the relationship to cyberspace. As far as these people are concerned, they do not feel they are being unfaithful.

The second type of online relationship is where people meet online but eventually want the relationship to move from the virtual to the actual after becoming emotionally intimate with each other online. The shared emotional intimacy often leads to cybersex and/or a strong desire to communicate constantly with each other on the Internet. For many, the online relationship will progress after sending photographs of each other into secret phone calls, letters, and offline meetings. Once they have met up, and if they are geographically near each other, their Internet use will usually decrease considerably as they will spend far more time actually (rather than virtually) with each other.

The third type of relationship is where two people first meet offline but then maintain their relationship online for the majority of their relationship. This is usually because they are geographically distant and may even be living in separate countries. These people only meet up a few times a year but may spend vast amounts of time "talking" to their partners on the Internet most nights. As they are geographically distant, the relationship only continues for those who have the time, the budget, and the travel opportunity to maintain the nominal physical contact. There are however possible downsides. For instance, there is anecdotal evidence that love over the Internet may lead to financial problems. One couple reported spending $£ 7000$ on their Internet relationship where their longest single conversation online was 17 hours and cost them $£ 330 .{ }^{46}$ They would spend an average of 7 hours a day typing to each other over the Internet and the male of the partnership went bankrupt.

With regards to "addiction," it is only the first type outlined here that may be addicted to the Internet. The latter two types are more likely to be addicted to the person rather than the activity-particularly as their Internet usage stops almost completely when they meet up offline with their partner.

\section{The downside of online relationships}

Online infidelity has accounted for a growing number of divorce cases according to the President of the American Academy of Matrimonial Lawyers. ${ }^{47}$ This is backed up by Young ${ }^{17}$ who claims that cyberaffairs exacerbate face-to-face relational problems and almost always adversely impact ongoing, longterm face-to-face relationships and cause marital discord, separation, and can even contribute to divorce.

Although many people who have not engaged in an online relationship fail to understand the pull and attraction of such an activity, it quite clearly can have detrimental consequences for some people who do. An online relationship can lead a loving and compassionate individual to become uncaring toward their partner and/or family, evasive, and demanding privacy online. In an effort to help both couples and therapists, Young et al, ${ }^{40}$ produced a list of early warning signs in the detection of a suspected online relationship. These include (a) a change in sleep patterns, (b) a demand for privacy, (c) ignoring other responsibilities, (d) evidence of lying, (e) personality changes, (f) loss of interest in sex, and ( $g$ ) declining investment in the relationship.

Griffiths ${ }^{27}$ has also reported case studies of excessive Internet users engaged in online relationships. However, these were not deemed by Griffiths to be addicted to the Internet. He claimed the excessive usage in these cases were purely symptomatic with the Internet being used to counteract other deficiencies in their lives (e.g., lack of human contact, physical appearance, disability, coping, etc.). However, it 
is interesting that most case studies cited in the academic literature used the computer excessively for social contact. As these cases show, text-based relationships can obviously be rewarding for some people. It is perhaps refreshing that in some circumstances, online relationships could be deemed to be psychologically healthy because they break down prejudices in that these intimate relationships are not based on people's physical appearance.

\section{SEXUALLY-RELATED INTERNET CRIME}

Despite the seemingly marked absence of serious consideration, sexually-related Internet crime seems set to become increasingly important to all those involved in the administration of criminal justice. The actual extent of this type of crime remains a somewhat elusive figure. However, most commentators assert that the extent of sexually-related Internet crime is on the increase and that some of the perpetrators may be addicted to the criminal activity in question and/or develop obsessions about their Internet victims. In the broadest possible sense, sexually-related Internet crime can be divided into two categories-(a) display, downloading and/or the distribution of illegal sexually-related material and (b) the use of the Internet to sexually procure and/or intimidate an individual in some way (e.g., online sexual harrassment, cyberstalking, paedophilic grooming).

Charlesworth ${ }^{48}$ noted that criminal law and those who enforce it have taken time to come to terms with the implications of change with regards to Internet crime. Those in the criminal justice system continue to rely on their own familiar scheme of reference when attempting to comprehend the criminal behavior. For the most part, they have some understanding of the mode of operation, likely benefits to the offender, and costs to the victim of the criminal activity presented before them. However, the unfamiliarity of sexually-related Internet crime denies those in the criminal justice system all important access to their own scheme of understanding. The reality is that advancements in computer technology generally, and the increased availability of the Internet in particu- lar, has provided for new innovations in, and an expansion of, the field of criminality (and more specifically in the area of sexually-related Internet crime). ${ }^{49-52}$

In the UK, most people's perceptions about sexually-related Internet crime are probably based around either the distribution of illegal pornography on the Internet and/or the use of the Internet for paedophilic purposes (for either distribution of child pornography or using the Internet to contact children with the paedophile pretending to be another child). The latest police guidelines in the United Kingdom also advise that anybody found to have used the Internet to view or circulate child pornography should be investigated as to whether they are abusing children. ${ }^{53}$

These perceptions are further enhanced from high profile cases such as the recent imprisonment of Graham Waddon. Waddon, the United Kingdom's largest pornography operator, was given an 18-month prison sentence for overseeing a large number of "cyber sin" sites from his house. In a short time, he made $£ 126,000$ from designing websites featuring extreme pornography, bestiality, coprophilia, and torture (e.g., Farmsex, Europerv, and Schoolgirls-R$U s)$ that were sent to Internet service providers in the United States for publication on the Web. ${ }^{54}$ The case will have wide ramifications as it is the first time a U.K. court has said that the authorities can prosecute those who publish obscene material even if they do it through Internet service providers abroad. One of the main problems is that any country's attempt to interdict cross-border flows of pornography would be defeated by advances in communication technology-especially data transmission. ${ }^{28,55}$ The police crackdown on Internet pornography has been argued by some to be futile as it could drive it underground. ${ }^{56}$ Part of the Internet's appeal is its subversive nature, for it crosses frontiers, language barriers, and is not policed by any one country.

Besides these serious offences, one area that has been given little consideration is that of online harassment in its many guises-some of which can escalate into full-blown stalking. This controversial area is examined in more detail in the following section. 


\section{Online harassment and cyberstalking}

Online harassment is certainly not a new phenomenon as there have been reported cases throughout the 1990s. For instance, Maxine Morse gave up her $£ 60,000$-a-year job when male colleagues at the company she worked at bombarded her E-mail address with images of bestiality and naked men taken from the Internet. She was awarded $£ 22,000$ in compensation $^{57}$ (also see Dibbell ${ }^{58}$ ).

Stalking has been a high-profile crime in the 1990s, leaving victims with a shattered sense of security and well-being. It now seems to be the case that stalkers are moving with the times and starting to harass and stalk in cyberspace. As a direct result of the increased accessibility of the Internet worldwide, the incidence of cyberstalking will almost certainly increase. Very recently, the first prosecution case of cyberstalking or harassment by computer occurred when Gary Dellapenta, a 50-year-old security guard, was arrested for his online activities in Los Angeles. ${ }^{59}$ Although such a phenomenon is by definition a global one, it was the Californian legal system that took the lead in an effort to combat it.

It all began when Dellapenta was rebuffed by his 28-year-old victim Randi Barber. As a result of this rejection, Dellapenta became obsessed with Barber and placed adverts on the Internet under the names "playfulkitty $4 U$ " and "kinkygal30" claiming she was "into rape fantasy and gang-bang fantasy." 59 As a result of these postings, she started to receive obscene phone calls and visits by men to her house making strange and lewd suggestions. Many other cases of cyberstalking and/or persistent and unwanted E-mail messages have also been reported. ${ }^{60,61}$

\section{Cyberstalking: How big is the problem?}

In 1998, Novell (one of the world's leading providers of network software) began a study in the United Kingdom into "spamming" (i.e., the receiving of unwanted and unsolicited cyber junk mail). The focus of the study was to estimate the cost in business terms of time and money wasted. However, one of the unexpected findings of the research was that a large minority of women, $41 \%$ of the regular Inter- net users, had been sent pornographic material or been harassed or stalked on the Internet. ${ }^{59}$ Three percent of these messages were highly personal and sexual, and 35\% of the messages were unsolicited pornography. Such unwarranted attention is intrusive and is a serious cause for concern.

CyberAngels (www.cyberangels.org) is a branch of the Guardian Angels and was set up in 1995. To date, it has dealt with over 200 cases of cyberstalking-two of which ended in the rape of the victims according to their Senior Director, Colin Gabriel Hatcher. ${ }^{51}$ The organization claims that cyberstalking usually occurs with women who are stalked by men, or by children who are stalked by adult predators. Typically, the victim is new online and therefore typically ignorant of "netiquette." In most cases, people just receive unsolicited junk-mail but it can turn sinister. The risk of harassment intensifies if someone enters a chat room. In most instances, the online harassment and stalking have eventually escalated offline. This is done by tracing the victim's telephone number and their address. Hatcher makes the point that cases such as these should not be trivialized as the paranoia of a small group of computer users. ${ }^{51}$ In the United States, libel and defamation are taken very seriously, but stalking is sometimes perceived as a crime related to women's hysteria.

In relation to cyberstalking, the normal police reaction (in the United States at least) appears to be one of non-seriousness. It is not uncommon for police to advise the victim to simply shut off of their computer. One infamous quote was attributed to a policeman who said "Are you afraid he's going to climb out of the monitor?" which completely missed the point. Cyberstalking forces people off the Internet, but the Internet is now an established part of many people's lives. In the future, the whole criminal justice system is going to have to treat this issue far more seriously.

One of the problems with Internet use is that there are always more novices than those experienced, so the novices are not being taught the ways that they can protect themselves from being exploited. At least with obscene phone calls there is a voice and with letters there is handwriting, with E-mails there is nothing to 
go on, no clue as to the personality of the person involved. To some this makes the whole thing creepier. What's more, these "new" criminals perhaps would never have interfered in other people's lives and committed such acts in a face-to-face scenario.

\section{Cyberstalking: What can be done to combat the problem?}

The development of computer technology is producing new categories of crimes in which the perpetrator believes they can hide behind the seemingly anonymous computer screen in an attempt to intimidate, threaten and spread hatred. These people appear to be naïve about exactly how anonymous they can be because specialists in this field can trace almost any electronic trail back to a computer. Every time a person visits a website, they are leaving their e-mail address behind as a calling card. If that person take part in any Internet discussions on a Usenet site, they are again leaving their identity. Where new crimes occur, new methods are used to combat it. For instance, a police officer was recently caught attempting to solicit minors over the Internet when pretending to be a 13-year old girl. ${ }^{59}$ This was easier to do over the computer than it would have been in real life. The International Web Police (www.WebPolice.org) are well-placed to fight this relatively new type of crime. The executive Director of the organization, Jeff Meyer, says they have been addressing stalkers since 1986 although very few of these cases concern cyberstalking. ${ }^{59}$

\section{Cyberstalking: Some conclusions}

At present very few cases of cyberstalking have reached U.K. courts although U.K. law is adequately equipped to deal with such scenarios because of the recent 1997 Protection From Harassment Act. There is no specific mention of computers in the Act but the definition of harassment is based on the "reasonable man" test (i.e., any action that would reasonably be considered to be harassment are caught within the Act). This so-called "stalking act" sets out to create both criminal and civil sanctions for harassment, and in so doing, builds upon existing common law nuisance actions. ${ }^{51}$ Crimi- nal law and those who enforce it must come to terms with the implications of change with regards to computer crime. It could be argued that the technical complexity associated with cybercrime combined with the limited number of prosecutions has permitted criminal justice practitioners the luxury of ignorance.

Sparrow and Griffiths ${ }^{30}$ have stated that if computer-related crime is to occupy a position of increasing importance in the range of offending behavior, then criminal justice practitioners must be willing to familiarize themselves with such activities in order to make judgements about the offender and the nature of their offending. One day cyberstalking may be viewed in the same way that other more "traditional" criminal acts are currently viewed.

\section{INTERNET SEXUALITY: FUTURE RESEARCH}

One of the objectives of any future research should be to determine the object of the Internet sex addiction. If some people appear addicted to the Internet, what are they addicted to? Is it the medium of communication (i.e., the Internet itself)? Aspects of its specific style (e.g., anonymity, disinhibition etc.)? The information that can be obtained (e.g., hard-core pornography)? Specific types of activity (genderswapping, role-playing games, playing sex computer games, cyberstalking)? Talking/ fantasizing to others (in chat rooms or on Internet Relay Chat)? Perhaps it could even be a complex interaction between more than one of these. It is most likely that the Internet provides a medium for the "addiction" to flow to its object of unhealthy attachment (i.e., a secondary addiction to more pervasive primary problems). The Internet can easily be the focus of excessive, addictive, obsessive and/or compulsive behaviors. One thing that may intensify this focus are the vast resources on the Internet available to feed or fuel other addictions or compulsions. For example, to a sex addict or a stalker, the Internet could be a very dangerous medium to users and/or recipients. There is also the problem that the Internet consists of many different types of activity (e.g., e-mailing, 
information browsing, file transferring, socialising, role-game playing etc.) and it could be the case (and probably is the case) that some of these activities (like Internet Relay Chat or role playing games) are potentially more addictive than some other Internet activities. It is also worth noting that there has been no research indicating that sexually-related Internet crimes such as cyberstalking are addictive. However, the small number of case studies that have emerged do appear to indicate that cyberstalkers display addictive tendencies at the very least (salience, mood modification, conflict etc.) although further research is needed to ascertain whether these excessive behaviors could be classed as bona fide behavioral addictions.

With regard to online relationships and affairs, these behaviors present a new dimension in couple relationships. These sexually-related Internet behaviors appear to range from healthy and normal through to unhealthy and abnormal (i.e., use, abuse, and addiction). ${ }^{13}$ The Internet is anonymous, disinhibiting, easily accessible/convenient, affordable, and escapefriendly. These appear to be some of the main reasons for online infidelity. The detection of online affairs may be difficult, but that does not mean it should not be given serious consideration in either an academic or practical context. These groups, along with those who engage in or who are on the receiving end of such behaviors, need to recognize that the Internet adds a new dimension to relationships. This has implications for assessment and treatment of couples who may, knowingly or unknowingly, undergo a relationship breakdown due to the impact of excessive online communication. However, as was noted earlier, text-based relationships can obviously be a positive and rewarding experience for many people. It is also an area in need of future research.

Interestingly, there is no clear evidence about the effects of pornography on users. ${ }^{62} \mathrm{How}^{-}$ ever, Young et al. ${ }^{40}$ quite rightly assert that future research is needed to more clearly delineate the identification and classification of problematic online sexual activities and that Cooper, Putnam, Planchon, and Boies ${ }^{\prime 13}$ proposed continuum of Internet sexual activities from life-enhancing to pathological needs to be replicated and further refined. There are very few areas surrounding excessive Internet use and its relationship with sexuality that do not need further empirical research (e.g., online sexual addiction, Internet and computer addiction, and online relationship dependency and/or virtual affairs). More remains to be done in cyberspace to more clearly understand both the risks and benefits for Internet users, couples, and society as a whole.

More research is also needed to examine the structural characteristics of the Internet and the things that appear on it. Griffiths ${ }^{19}$ has speculated the structural characteristics of the some kinds of software might promote addictive tendencies. Structural characteristics (i.e., features that manufacturers design into their products) promote interactivity and to some extent define alternative realities for the user and allow them feelings of anonymity in features that may be very psychologically rewarding. For instance, determinants of the decision to engage in a particular activity not only include the person's biological and psychological constitution and the situational variables, but also the structural characteristics of the activity itself. As Griffiths ${ }^{63}$ points out, the structural characteristics of particular activities are responsible for reinforcement, may satisfy users' needs and may actually facilitate excessiveness. By identifying particular structural characteristics it, may be possible to see how (a) needs are identified, (b) information about the Internet is presented (or perhaps misrepresented), and (c) cognitions are influenced and distorted (see Griffiths ${ }^{63}$ for an overview on structural characteristics).

There is no doubt that Internet usage among the general population will continue to increase over the next few years. Social pathologies relating to Internet sexual behavior do exist. This is certainly an area that should be of interest and concern not only to psychologists but to all those involved in clinical health issues. Excessive use of the Internet is not problematic in most cases, but the limited case study evidence available does suggest that excessive Internet usage is a real addiction and of genuine concern for some individuals. 


\section{REFERENCES}

1. Walker, M.B. (1989). Some problems with the concept of "gambling addiction": Should theories of addiction be generalized to include excessive gambling? Journal of Gambling Behavior 5:179-200.

2. Rachlin, H. (1990). Why do people gamble and keep gambling despite heavy losses? Psychological Science 1:294-297.

3. Miller, W.R. (1980). The addictive behaviors. Oxford: Pergamon Press.

4. Orford, J. (1985). Excessive appetites: A psychological view of the addictions. Chichester: Wiley.

5. Marks, I. (1990). Non-chemical (behaviourial) addictions. British Journal of Addiction, 85:1389-1394.

6. Griffiths, M.D. (1996). Behavioural addictions: An issue for everybody? Employee Counselling Today: The Journal of Workplace Learning, 8(3):19-25.

7. Griffiths, M.D. (1996). Internet "addiction": An issue for clinical psychology? Clinical Psychology Forum, 97:32-36.

8. Griffiths, M.D. (1997). Psychology of computer use: XLIII. Some comments on "Addictive use of the internet" by Young. Psychological Reports, 80:81-82.

9. Griffiths, M.D. (1997). Technological addictions: Looking to the future. Paper presented at the 105th Annual Convention of the American Psychological Association, Chicago, IL.

10. Griffiths, M.D. (1998). Internet addiction: Does it really exist? In: Gackenbach, J., (ed.) Psychology and the Internet: Intrapersonal, interpersonal and transpersonal Applications. New York: Academic Press, pp. 61-75

11. Brenner, V. (1997). Psychology of computer use: XLVII. Parameters of internet use, abuse and addiction: The first 90 days of the internet usage survey. Psychological Reports, 80:879-882.

12. Cooper, A. (1998). Sexuality and the Internet: Surfing into the new millennium. CyberPsychology and Behavior, 1:181-187.

13. Cooper, A., Putnam, D.E., Planchon, L.A., \& Boies, S.C. (1999). Online sexual compulsivity: Getting tangled in the net. Sexual Addiction \& Compulsivity: The Journal of Treatment and Prevention, 6:79-104.

14. Cooper, A., Scherer, C., Boies, S.C., \& Gordon, B. (1999). Sexuality on the internet: From sexual exploration to pathological expression. Professional Psychology: Research and Practice, 30:154-164.

15. Morahan-Martin, J.M., Schumacher, P. (1997). Incidence and correlates of pathological internet use. Paper presented at the 105th Annual Convention of the American Psychological Association, Chicago, IL.

16. Scherer, K. (1997). College life online: Healthy and unhealthy Internet use. Journal of College Development, 38:655-665.

17. Young, K. (1998). Internet addiction: The emergence of a new clinical disorder. CyberPsychology and Behavior, 1:237-244.

18. Young, K. (1998). Caught in the Net: How to recognize the signs of Internet addiction and a winning strategy for recovery. New York: Wiley.
19. Griffiths, M.D. (1995). Technological addictions. Clinical Psychology Forum, 76:14-19.

20. Griffiths, M.D. (1996). Nicotine, tobacco, and addiction. Nature, 384:18.

21. Young, K. (1999). Internet addiction: Evaluation and treatment. Student British Medical Journal, 7:351-352.

22. Griffiths, M.D. (1999). Internet addiction: Internet fuels other addictions. Student British Medical Journal, 7:428-429.

23. Griffiths, M.D. (1995, April 7). Netties anonymous. Times Higher Educational Supplement, p. 18.

24. Young, K. (1999). Cyber-disorders: The mental illness concern for the millennium. Paper presented at the 108th Annual Meeting of the American Psychological Association, Boston, MA.

25. Scherer, K., Bost, J. (1997). Internet use patterns: Is there internet dependency on campus? Paper presented at the 105th Annual Convention of the American Psychological Association, Chicago, IL.

26. Moore, D. (1995). The emporor's virtual clothes: The naked truth About the Internet culture. Chapel Hill, NC: Alogonquin.

27. Griffiths, M.D. (2000). Does internet and computer "addiction" exist? Some case study evidence. CyberPsychology and Behavior, 3:211-218.

28. Sprenger, P. (1999, September 30). The porn pioneers. The Guardian (Online), p. 2-3.

29. Blue money. (1999, May 27). The Guardian (Online), p. 5.

30. Sparrow, P., \& Griffiths, M.D. (1997). Crime and IT: Hacking and pornography on the internet. Probation Journal, 44:144-147.

31. Veash, N. (1999, August 29). Prostitutes target Internet lonely hearts. The Independent on Sunday, p. 5.

32. Cooper, A., Delmonico, D., \& Burg, R. (In press). Cybersex users, abusers, and compulsives: New findings and implications. Sexual Addiction \& Compulsivity: The Journal of Treatment and Prevention.

33. Brooks, M. (1999, September 30). Sex site surfers teach traffic watchers. The Guardian (Online), p. 3.

34. Thompson, B. (1999, June 24). New kids on the net. The Guardian (Online), p. 2-3.

35. Lillington, K. (1999, September 9). Web life: Parenting. The Guardian (Online), p. 5.

36. Griffiths, M.D. (1997). Children and the internet. Media Education Journal, 21:31-33.

37. Griffiths, M.D. (1998). Children and the internet: Issues for parents and teachers. Education and Health, 16:9-10.

38. McClellan, J. (1997, February 6). Love caught in the net. The Guardian (Online), p. 2-3.

39. Griffiths, M.D. (1999). All but connected (Online relationships). Psychology Post, 17:6-7.

40. Young, K.S, Griffin-Shelley, E., Cooper, A., O'Mara. J., \& Buchanan, J. (In press). Online infidelity: A new dimension in couple relationships with implications for evaluation and treatment. Sexual Addiction and Compulsivity.

41. Ried, E. (1994). Cultural formations in text-based virtual 
realities. Online document: $\underline{\mathrm{http}: / / \text { people.we.mediaone. }}$ net/elizrs/work.html

42. Joinson, A. (1998). Causes and implications of disinhibited behavior on the Internet. In: Gackenback, J., (ed.) Psychology and the Internet: Intrapersonal, interpersonal, and transpersonal implications. New York: Academic Press, pp. 43-60.

43. Cooper, A., \& Sportolari, L. (1997). Romance in cyberspace: Understanding online attraction. Journal of Sex Education and Therapy, 22:7-14.

44. Griffiths, M.D. (In press). Gambling technologies: Prospects for problem gambling. Journal of Gambling Studies.

45. King, S.A. (1999). Internet gambling and pornography: Illustrative examples of the psychological consequences of communication anarchy. CyberPsychology \& Behavior, 2:175-193.

46. Barry, R. (1996, November 21). High cost of loving. The Guardian (Online), p. 5.

47. Quittner, J. (1997, April 14). Divorce Internet style. Time, p. 72.

48. Charlesw orth, A. (1995, May 10). Never having to say sorry. The Times Higher Educational Supplement (Multimedia Section), p. viii.

49. Durkin, K.F. (1997). Misuse of the Internet by pedophiles: Implications for law enforcement and probation practice. Federal Probation, 61(3):14-18.

50. Durkin, K.F., \& Bryant, C.D. (1998). Propagandizing pederasty: A thematic analysis of the on-line exculpatory accounts of unrepentant pedophiles. Deviant Behavior, 20:103-127.

51. Griffiths, M.D., Rogers, M.E., \& Sparrow, P. (1998). Crime and IT (Part II): "Stalking the Net." Probation Journal, 45:138-141.

52. Deirmenjian, J.M. (1999). Stalking in cyberspace. Journal of the American Academy of Psychiatry and the Law, 27:407-413.

53. Brindle, D. (1999, August 28). Net child porn users face abuse checks. The Guardian, p. 15.
54. Wilson, J. (1999, October 7). Net porn baron escapes jail. The Guardian, p. 5.

55. Millar, S. (1996, September 2). Police curb on Net porn "impossible." The Guardian, p. 6.

56. Booth, N. (1996, August 16). Clampdown can easily be beaten, say net experts. The Times, p. 2.

57. Woman harassed by computer porn. (1996, October 4). The Times, p. 5.

58. Dibbell, J. A rape in cyberspace: How an evil clown, a Haitian trickster, spirit, two wizards, and a cast of dozens turned a database into a society. Online document: http://www.levity.com/julian/bungle vv.html

59. Gumbel, A. (1999, January 31). Techno detectives net cyber-stalkers. Independent on Sunday, p. 17.

60. Millbank, J. (1999, March 21). "My terror stalked by e-mail nut." News of the World, p. 23.

61. Tran, M. (1998, March 26). Trial by e-mail. The Guardian (Online Section), p. 4.

62. Barak, A., Fisher, W.A., Belfry, S., \& Lashambe, D.R. (1999). Sex, guys, and cyberspace: Effects of Internet pornography and individual differences on men's attitudes toward women. Journal of Psychology $\mathcal{E}$ Human Sexuality, 11:63-91.

63. Griffiths, M.D. (1993). Fruit machine gambling: the importance of structural characteristics. Journal of Gambling Studies, 9:133-152.

Address reprint requests to: Dr. Mark Griffiths Psychology Division Nottingham Trent University Burton Street Nottingham, NG1 $4 B U$ United Kingdom

E-mail: mark.griffiths@ntu.ac.uk 